\title{
Dermoscopy in the era of dermato-oncology: from bed to bench side and retour
}

\author{
Nora Woltsche, Christoph Schwab, Teresa Deinlein, Rainer Hofmann- \\ Wellenhof \& Iris Zalaudek
}

To cite this article: Nora Woltsche, Christoph Schwab, Teresa Deinlein, Rainer Hofmann-Wellenhof \& Iris Zalaudek (2016): Dermoscopy in the era of dermatooncology: from bed to bench side and retour, Expert Review of Anticancer Therapy, DOI: $\underline{10.1586 / 14737140.2016 .1168700}$

To link to this article: http://dx.doi.org/10.1586/14737140.2016.1168700

Accepted author version posted online: 21

Mar 2016.

Submit your article to this journal $๘$

Џ Article views: 1

Q View related articles $\sqsubset$

View Crossmark data $\nearrow$ 
Publisher: Taylor \& Francis

Journal: Expert Review of Anticancer Therapy

DOI: $10.1586 / 14737140.2016 .1168700$

Review

Dermoscopy in the era of dermato-oncology: from bed to bench side and retour

\begin{abstract}
Today dermoscopy is standard-of-care in the diagnosis and management of patients with benign and malignant skin tumors because it increases the diagnostic accuracy of skin lesions compared to the nakedeye examination up to $25 \%$. Despite its role in the routine dermato-oncology, it increasingly gained interest as a bridge connecting clinical with basic molecular research in dermato-oncology. Here, we correlate dermoscopy patterns of nevi and melanomas with high and low susceptibility genes and somatic mutations, provide an overview on the clinical and dermoscopic patterns of cutaneous melanoma subtypes, and highlight the role of dermoscopy in the diagnosis of skin eruptions during systemic treatments of advanced melanoma including targeted therapies and immunotherapies.
\end{abstract}

\title{
Keywords
}

Dermoscopy, nevi, melanoma, genetics, targeted therapy, immune checkpoint inhibitors 


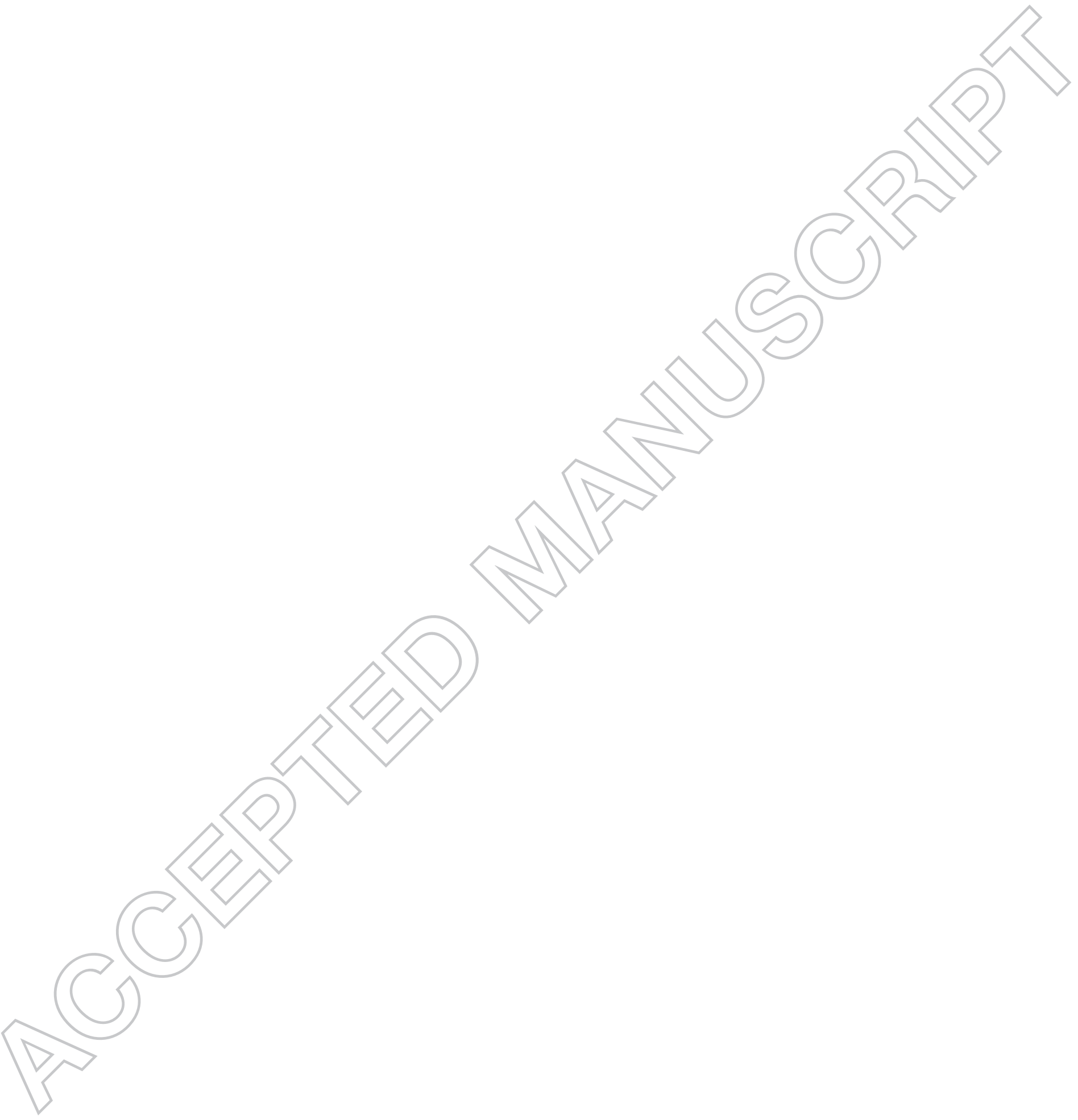




\section{Introduction:}

Dermoscopy is a non-invasive technique that aids to increase the diagnostic accuracy of skin lesions of the naked eye $(1,2)$. The technique is now standard of diagnostic care in the setting of dermato-oncology and is recommended by most recent melanoma guidelines (3). However, dermoscopy is not only limited to clinical diagnosis. Today, represents a bridge between clinical and basic research as well as in the management of patients receiving systemic treatment for advanced skin cancer.

In this article, we provide an overview on dermoscopy as a link between clinical and basic research in dermato-oncology, whereby we pay emphasis on melanocytic skin tumors.

\section{High and low susceptibility genes and dermoscopy:}

Much research has focused on genetical alterations disposing to melanoma and cancer syndromes. High-penetrance alleles such as CDKN2A and CDK4, but also BAP1, POT1, ACD, TERF2IP, MITF and TERT $(4,5)$ are rare but have large effects whereas moderately to low penetrant genes like MC1R are more common and have been related to pigmentation traits, nevus counts, immune responses, DNA repair, and metabolism (6).

\section{Skin type related dermoscopic features of nevi:}

Number, dermoscopic-histopathologic features but also size and color of melanocytic nevi are strongly influenced by the pigmentary trait of a given individual. Nevi in persons with a fair skin type are generally large ( $>5 \mathrm{~mm})$, slightly elevated, red to light brown dermoscopically characterized by a structureless red to light brown pigmentation or a network pattern with a central hypopigmentation. Histopathologically, they correlate with intradermal or compound nevi. In contrast, dark skinned individuals often exhibit small $(<5 \mathrm{~mm})$, flat, dark brown junctional nevi with a dermoscopic network pattern showing a central hyperpigmentation (Figure $1 \mathrm{~A}-\mathrm{D}$ ). These differences suggest a role of pigmentary genes in melanocyte migration and differentiation during embryogenic nevogenesis $(7,8)$.

\section{Human pigmentation genes and dermoscopic patterns of melanoma:}

Cuellàr et al. were the first to demonstrate a direct effect of MC1R variants on the dermoscopic appearance of melanomas (9). In their pivotal study including 9 patients with a CDKN2A mutation (3 noncarriers of the red hair MC1R polymorphism, 3 patients with one red hair MC1R polymorphism and 3 
patients with two red hair MC1R polymorphisms) they found that the ABCD total dermoscopy score (ie., an algorithm scoring different melanoma-specific criteria; TDS) for melanomas was significantly higher in noncarriers of red hair MC1R polymorphisms than in carriers of two MC1R gene red hair variants. Moreover they highlighted the role of digital follow up in the management of these patients (Figure 2).Subsequent studies largely confirmed this preliminary observation (9-16). Fargnoli et al. investigated the TDS scores in 64 melanomas of 62 patients and also concluded that melanomas of MC1R red hair polymorphism (R) carriers show a significant lower TDS value, mainly due to reduced dermoscopic structures such as atypical pigment network and color variegations compared to non-carriers of MC1R R (12).

Quint et al. extended the knowledge on the association of red hair color (RHC) variants in the MC1R on both, nevi and melanomas (14). Their analysis of 876 atypical nevi and 21 melanomas revealed that pigment network, dark-brown color and streaks were more frequently observed in nevi from individuals without RHC variants, while structureless areas were more often observed in individuals with two RHC variants. (14). In another study investigating the dermoscopic features of 62 nevi in 27 patients with multiple melanomas, vessels were more frequently seen among CDKN2A G101W mutation carriers, while atypia was associated with any MC1R variant (13). In line with these findings, also Zalaudek et al. reported the association of RHC variants with the development of two primary "red" (amelanotic) melanomas and "white" (hypopigmented) dysplastic nevi (16).

\section{Germline mutations and morphology:}

De Giorgi et al. analyzed the dermoscopic images in 12 patients with multiple primary melanomas and reported in about $77 \%$ of cases on an unspecific dermoscopic pattern (17). Moreover, all patients with a CDKN2A germline mutation in this study developed multiple primary melanomas with a striking similar dermoscopic and histopathologic appearance (17).

More recently, Orlow et al. linked MC1R and 85 other candidate loci in a cohort of 353 children with nevus count and dermoscopic appearance of nevi (10). In this study, IRF4 rs12203952 polymorphism was very strongly associated with nevus count, while the rs12203952 T allele was associated with increased flat nevus count and decreased counts of raised nevi. Moreover, SNPs in IRF4 and TERT were significantly 
associated with a globular pattern, while SNPs in CDKN1B, MTAP and PARP1 showed significant associations with reticular-patterned nevi compared with homogeneous-patterned nevi. No association has however been found regarding the dermoscopic nevus pattern and nevus count and MC1R RH variants.

In another study evaluating the phenotypic characteristics of168 patients with melanoma and 126 unaffected individuals, the authors reported a higher nevus count of predominant reticular dermoscopic nevus pattern among five of six individuals, who were carriers of the rare MITF E318K germline mutation (18). Remarkably, a high incidence of amelanotic melanomas was found within the group, which suggests a genetic interaction between the MITF E318K allele and an MC1R homozygous red hair color (RHC) variant genotype.

A similar findings has been recently reported by Potrony et al. (19), who found MITF E318K being significantly associated with an increased melanoma risk, development of more than one melanoma and high nevus count (>200 nevi). Of note, they observed two fast-growing melanomas among 2 MITF p.E318K carriers during dermatologic digital follow-up.

Wiesner et al. described for the first time two families with inactivating germline mutations of the BAP1 gene characterized by multiple skin-colored, elevated melanocytic tumors (20). These melanocytic neoplasms, nowadays also commonly referred to as "Bapomas", revealed histopathologically epithelioid to atypical features with overlapping features with melanoma. Although up to date dermoscopic features have been described in these neoplasms, it is our experience that they exhibit structureless red to pink areas eventually associated with atypical vessels. Some affected patients also developed uveal or cutaneous melanomas. These findings were subsequently confirmed by an increasing number of publications and suggest that loss of BAP1 is associated with a clinically and morphologically distinct type of melanocytic neoplasms including uveal melanoma (20).

\section{Somatic mutations and dermoscopy of nevi:}

There is mounting evidence that the epidemiology, morphology and growth dynamics of nevi and melanomas correlate with different types of somatic mutations (21-24) (Figure 3). In the realm of melanocytic nevi, it has been shown that intermediate to large congenital melanocytic nevi more frequently harbor mutations in the NRAS gene compared to small congenital and acquired nevi, 
dermoscopically characterized by a globular or structureless brown pattern, which most commonly reveal mutations in BRAF V600E (25-29).

The fact that the latter both entities share the same mutation is interesting in the context that both also reveal overlapping features upon histopathology and dermoscopy, which do not allow a reliable differentiation between them in the absence of an according history $(22,30)$. The overlapping morphological and genetic characteristics along with an uncertain risk of malignant transformation of both, small congenital and acquired nevi, therefore questions the usefulness of their current classification into two different subclasses (22).

Besides small and acquired nevi, recent studies showed a high frequency of BRAF V600E mutations also in actively growing compound nevi, which are dermoscopically typified by a peripheral rim of brown globules (21). Based on digital dermoscopic follow up studies, it has been shown that these nevi enlarge over time until the final disappearance of globules indicates stabilization of growth (21). At this stage, nevi mostly exhibit a uniform or mixed reticular pattern with the latter showing either central globules or structureless areas (21). Remarkably, while growing nevi harbor BRAF V600E mutations at high frequency, the frequency of the mutation in stable nevi decreases (21). This observation along with data from basic research suggesting polyclonality for BRAF mutation in nevi (31), has led to the hypothesis that BRAF initially drives melanocyte proliferation (21). However after limited cell cycle rounds, cells will enter oncogene-driven senescence (21-24).

Conversely, atypical Spitz tumors and blue nevi have been linked with mutations in HRAS and GNAQ, respectively $(29,32)$, whereby one study reported on GNAQ mutations in about $83 \%$ of blue nevi (33) (Figure 3 C-D). Moreover, GNAQ seems involved also in initiation of ocular melanoma and with darkpigmented dermal melanoma (33).

\section{Somatic mutations and dermoscopy of melanoma:}

Recently, it has been shown that melanomas with BRAF V600E or NRAS mutations reveal dermoscopic signs of regression (peppering) at higher frequency compared to melanoma, which are wildtype (wt) for the mutations (34). The authors concluded that this finding might point toward a possible immune behavior in BRAF/NRAS mutated melanomas. 
Tschandl et al. investigated the frequency of BRAF mutations in nevus associated melanomas and uninvolved nevi of the same patient and detected BRAF V600E mutations in $63.0 \%$ of melanomas, $65.2 \%$ of associated nevi and $50.0 \%$ of control nevi (35). The authors concluded that these findings do not support the traditional model of stepwise tumor progression, with BRAF V600E representing an initial driver event in melanoma progression. The same group investigated also the impact of oncogenic BRAF V600E mutations and p16 expression on the growth rate of early melanomas and nevi in vivo (36). Expression of BRAFV $600 E$ and the loss of p16 were associated with an accelerated growth rate of early melanomas in digital dermoscopic monitoring but not in melanocytic nevi.

Instead, melanomas with a dermoscopically dark homogeneous streak pattern have been recently linked to a specific KIT mutation (37). This finding is consistent with a previous report showing that KIT was mutated/overexpressed in darkly pigmented cutaneous melanomas (38).

Integrating clinical and molecular findings into melanoma classification:

It must be acknowledged that term melanoma refers to a heterogeneous group of melanocytic proliferations that differ significantly with respect to their morphology, epidemiology, growth rate and capacity metastasize. Currently, different schemes are applied depending on the employed method to obtain information. As such melanomas can be classified based on morphological criteria (clinicaldermoscopic-histopathological), growth rate (slow and fast growing), sites of origin (chronic, intermittent, no UV-exposure) and genetical alterations (39-42). Using a combined classification approach that integrates clinical morphology with epidemiology and genetics, the following melanoma subtypes can be distinguished (Figure 4).

\section{Slow growing melanoma:}

There is mounting evidence for the existence of a group of melanomas characterized by a slow in

situ growth over a long period of time and low metastatic potential (43-45). This subtype can be considered equivalent to lentiginous or superficial spreading melanoma and has been associated with a strong increase in incidence, development on intermittent sun-exposed areas, a high nevus count, and mutations in the BRAF V600E gene (46). 
Clinically this melanoma frequently exhibits the 3 or more criteria of the $A B C D E$ rule such as asymmetry, border irregularity, color variegations, diameter more than $6 \mathrm{~mm}$ and evolution over time.

Dermoscopically, it is characterized by a network pattern and areas of regression (characterized by white structureless areas and gray dots). Direct proof for the existence of such slow growing melanoma is achieved by digital dermoscopic monitoring studies showing only subtle changes during a mean follow up of 20 months $(44,45)$. (Fig.5)

\section{Fast growing melanoma:}

Fast growing melanoma can be regarded equivalent to nodular melanoma, which is a rapidly progressing and potentially lethal skin tumor (47). Some question whether nodular or fast growing melanoma arises from the epidermis or develops initially in the dermis (48) (Figure 6). It shows a relatively stable incidence and is neither associated with a specific sun-exposure pattern, high nevus count nor with specific mutations, although NRAS mutations appear more commonly in this subtype than in others (49).

The EFG (elevation, firm on palpation and continuous growth for more than 1 month) rule has been proposed for its clinical diagnosis (50). Fast growing melanoma can be heavily pigmented or amelanotic.

The blue and black rule is an easy dermoscopic clue to diagnose fast growing pigmented/ nodular melanoma and refers to the contemporary presence of structureless blue areas intermingled with black dots/globules/blotches or bizarre structures $(51,52)$. Of note, the histopathological correlates of black structures are either hemoglobin or melanin in the upper epidermis, whereby this can be due to ulceration, pigmented parakeratosis, pagetoid spread of melanocytes or to large nests of heavily pigmented melanoma cells just beneath a very thinned epidermis, respectively. Especially the latter feature has been discussed as predictive feature for developing ulceration before it becomes clinically manifest $(52,53)$. Further patterns that occur at variable frequency are asymmetric pigmentation, disorganized polychromatic patterns, grey/blue structures, white short lines using cross polarized light, peripheral black dots/globules, largediameter vessels and milky red areas $(47,54-57)$.

In contrast, amelanotic fast growing melanoma reveals atypical vascular structures like polymorphous vessels (dotted and linear), milky-red globules/areas and homogeneous red/pink areas $(58,59)$. 


\section{Lentigo maligna melanoma:}

Lentigo maligna (LM) belongs to a group of very slow growing melanomas and may remain in this in situ phase for years, if not decades (60). LM shows a slight increased incidence over the past decades and is strongly associated with chronic sun-exposure, but not with a high nevus count or mutations in BRAF or NRAS or KIT.

The diagnosis of LM remains challenging even if coupled with dermoscopy, because most criteria overlap also with other pigmented facial macules such as pigmented actinic keratosis or solar lentigo $(48,61-66)$. However, it has been shown that grey color is the single most important dermoscopic criterion for diagnosing lentigo maligna melanoma. $(67,68)$ (Figure 7).

\section{Acral-lentiginous melanoma:}

Acral lentiginous melanoma can be regarded a melanoma subtype of likely intermediate growth that arises from the glabrous skin of the soles and palms or from the nail matrix (i.e., subungual melanoma). It has a stable incidence but no association with sun-exposure or with a high nevus count. Mutations, if present, involve KIT or cyclin D1 $(41,69)$.

\section{Acral melanoma:}

Acral melanoma arising from the glabrous skin presents typically as large, inhomogeneouspigmented macule or plaque measuring more than $7 \mathrm{~mm}$ (70). Dermoscopically, early acral melanoma exhibits a parallel-ridge pattern, composed by broad parallel pigmentation lines that are seen in correspondence to the ridges of the glabrous skin (Figure 8 A-B). This pattern achieves a very high specificity and sensitivity ( $99 \%$ and $86.4 \%$, respectively) for the diagnosis (71). Very recently, a scoring system (named BRAAFF) composed of six variables was proposed for the diagnosis of AM. This method

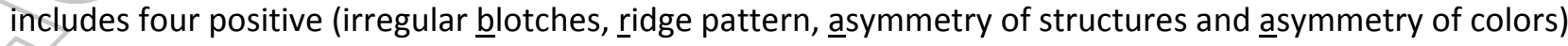
and two negative predictors (f́urrow pattern and fibrillar pattern) (72).

Of particular interest is the study by Yamaura et al., who investigated the dermoscopic patterns and amplifications in the cyclin D1 gene in 16 histopathologically equivocal, acral melanocytic skin lesions (73). Nine of these 16 lesions exhibited the parallel ridge pattern by dermoscopy suggestive for melanoma 
in situ, and 4 (44\%) of them had also amplifications of the cyclin D1 gene. Amplifications were not found in any of the remaining 7 lesions that showed dermoscopic patterns suggestive of a benign melanocytic nevus (fibrillar, parallel furrow or lattice like pattern).

Based on these finding, the authors concluded that cyclin D1 gene amplification and a dermoscopic parallel ridge pattern can be identified in a very early progression phase of acral melanoma that precedes histopathologically defined melanoma in situ.

\section{Subungual melanoma:}

The so-called ABCDEFG rule has been proposed to memorize the most salient clinical and epidemiological data of this melanoma subtype (74). In this system, A refers to either to age (peak incidence after $5^{\text {th }}$ decade of life) or African Americans, Asians, and native Americans. B stands for brown to black band-like pigmentation with a breadth of $3 \mathrm{~mm}$ or more. $\mathrm{C}$ stands for change in the nail plate while $\mathrm{D}$ stands for the first digit most commonly involved; E stands for extension of the pigment onto the proximal and/or lateral nailfold (ie, Hutchinson's sign); and F stands for family or personal history of dysplastic nevus or melanoma.

Dermoscopically, early subungual melanoma reveals a band like pigmentation composed by lines of different width and color (75) (Figure 8 C-D).

\section{Mucosal melanoma:}

Similar to acral lentiginous melanoma, also mucosal melanoma lacks association with UV-expose or multiple nevi and harbors most commonly KIT mutations (41). Dermoscopically, this melanoma subtype commonly reveals a combination of blue, gray or white color (76), whereby the frequency of dermoscopic patterns is influenced by the tumor thickness $(77,78)$.

A study including melanomas of the oral and genital mucosa and semi-mucosa revealed that $75 \%$ of

these lesions presented with a multi-component pattern and only $25 \%$ with a homogeneous pattern in dermoscopy $(79,80)$.

\section{Dermoscopy of secondary skin neoplasms related to the systemic treatment of advanced melanoma}

\section{Alterations in melanocytic lesions under targeted therapy:}


Among a number of cutaneous side-effects during Braf-Inhibitor treatment (BRAFi) with vemurafenib are alterations of the melanocyte and keratinocyte system (Figure 9 A-D). These include growth and involution of new and pre-existing nevi, respectively as well as the development of new melanomas either de novo or within pre-existing nevi $(81,82)$.

Up to date, newly evolving nevi under BRAFi therapy were shown to be wildtype with regard to the mutation, while stable or involuting nevi harbor the mutation (83).

In line with a study correlating the dermoscopic features of nevi with BRAF mutations (84), involuting nevi under vemurafenib treatment typically reveal a globular and/or structureless brown pattern upon dermoscopy, while conversely, newly developing BRAFwt nevi are characterized by a reticular pattern (85) (Figure 9 A).

Interestingly, Dalle S et al. were the first reporting on the development of melanomas in patients receiving vemurafenib for metastatic melanoma (86). In detail, they reported on 6 early BRAFwt primary melanomas evolving from 6 atypical melanocytic lesions in 4 patients 4 to 12 weeks after initiation of vemurafenib therapy (87) (Figure 9B).

Subsequent publications confirmed the development of second primary melanomas either de novo or from pre-existing lesions under BRAFi therapy, which are all wt for the mutation $(81,88-94)$.

However, there are two aspects with regard to these findings that should receive special attention: First, nevi initially lacking atypia have been shown to develop striking atypia under BRAFi therapy (92). Second, the reported incidence of second primary melanomas in patients receiving vemurafenib is unexpected higher (21\%) compared to the general population (estimated 5\%) (88).

Although it might be possible that these second primary melanomas could present initially dormant, but due BRAFi paradoxically activated melanomas, another plausible explanation has been postulated by another group (94), who question whether these melanomas should be rather regarded drug-activated nevi showing marked atypia as it is also reported in other activated nevi such as after UVexposure, epidermolysis bullosa nevi or recurrent nevi.

\section{Squamous cell carcinoma under BRAFi therapy}


The development of cutaneous squamous cell carcinomas and keratoacanthomas was reported under vemurafenib and to much lesser extend under dabrafenib therapy $(93,95)$. These tumors are characterized by white circles, white structureless areas, hairpin vessels or coiled vessels, scales and central masses of keratin appearing as yellow to white structureless areas with splitter hemorrhages (Figure $9 \mathrm{C}$ ).

\section{Inflammatory skin reactions under BRAFi therapy}

Another commonly observed adverse effects affecting the skin under vemurafenib therapy is acantholytic dyskeratosis $(96,97)$. Also for this condition, specific dermoscopic patterns have been described, which consists of a yellow opaque star-like center with a white outline overlying a red to brown area (Figure 9D) (98-100).

\section{Cutaneous eruptions under check point blockade therapy}

Among series of reported cutaneous side effects under immunotherapy using CTLA-4 antibodies, PD-1 inhibitors and PDL-1 inhibitors are lichenoid eruptions (101).

Dermoscopy for their diagnosis is of particular value as dermoscopic patterns of lichen planus are highly specific and consist of white crossing lines (corresponding to the histopathological correlate of the Wickham striae) over a typically reddish to violaceous background with some dotted vessels (102).The specific features originally described for lichen ruber planus, allowing also a reliable diagnosis of lichenoid eruptions in patients receiving immunotherapy for metastatic melanoma (Figure $10 \mathrm{~A}-\mathrm{D}$ ).

\section{Expert commentary}

Dermoscopy is a widely accessible, fast and non-invasive diagnostic method that improves the clinicians' ability to diagnose skin cancer at an earlier stage compared to the unaided eye. The use of digital dermoscopic monitoring has allowed for the identification of specific dermoscopic patterns predictive for the growth of both, nevi and melanoma. The increasing knowledge that specific molecular alterations correlate with specific clinical morphologies is of interest for clinical and basic research but also for the practical management of patients. 


\section{Five-year view}

Dermoscopy, but also more recent non-invasive skin imaging tools such as confocal microscopy, or optical coherence tomography will increasingly improve the understanding of melanocytic morphology and biology. Currently there is much research ongoing focusing on the identification of biomarkers predictive for response to treatment. Whether or not specific morphological patterns may become useful as biomarkers in the future remains at current an open question. However, first studies in this field suggesting specific morphological patterns associated with specific molecular alterations point towards such possibility. A further very intriguing era of research will be the in vivo observation of changes during treatment, which might further open new insights into the developmental steps of melanocytic skin tumors and the interaction between the melanocyte and keratinocyte system. Overall, it can be however previewed that dermoscopy will not be replaced in the next 5 years as routine tool for skin cancer screening, but new methods might be considered important adds on to improve the knowledge about growth rate and response to treatment.

\section{Key issues}

- Dermoscopy is a standard technique that improves the clinicians' accuracy to diagnose and manage skin tumors compared to the naked-eye examination.

- Dermoscopy is integrative part of the management in dermato-oncology

- Genetical alterations correlate well with morphology or specific topographies of melanocytic skin tumors

Nevi as well as melanomas in carries of the red hair polymorphism of the MC1R gene often reveal structureless light brown to red color BRAF V600E is the most common mutation in nevi and melanoma. In both, the presence of the mutation is correlated to specific dermoscopic features

- The classification of melanoma is an evolving science and correlates morphological aspects of melanoma with biological behavior and molecular alterations 
- Dermoscopy aids the diagnosis and management of dermatological adverse effects during novel targeted and immune therapies.

\section{Financial and competing interests disclosure}

The authors have no relevant affiliations or financial involvement with any organization or entity with a financial interest in or financial conflict with the subject matter or materials discussed in the manuscript. This includes employment, consultancies, honoraria, stock ownership or options, expert testimony, grants or patents received or pending, or royalties.

\section{References}

(1) Vestergaard ME, Macaskill P, Holt PE, Menzies SW. Dermoscopy compared with naked eye examination for the diagnosis of primary melanoma: a meta-analysis of studies performed in a clinical setting. Br J Dermatol. 2008;159:669-676.** Meta-analysis showing a significant superiority in the diagnostic accuarcy of dermoscopy compared to naked eye examination

(2) Kittler H, Pehamberger H, Wolff K, Binder M. Diagnostic accuracy of dermoscopy. Lancet Oncol. 2002;3:159-165.

(3) National Collaborating Centre for Cancer: Melanoma - assessment \& management, NICE guideline NG14, July 2015.

(4) Aoude LG, Wadt KAW, Pritchard AL et al. Genetics of familial melanoma: 20 years after CDKN2A. Pigment Cell Melanoma Res. 2015;28:148-160.

(5) Read J, Wadt KAW, Hayward NK. Melanoma Genetics. J Med Genet. 2016;53:1-14.

(6) Ward KA, Lazovich D, Hordinsky MK. Germline melanoma susceptibility and prognostic genes: a review of the literature. J Am Acad Dermatol. 2012;67:1055-1067.

(7) Zalaudek I, Argenziano G, Mordente I, Moscarella E, Corona R, Sera F, Blum A, Cabo H, Di Stefani A, Hofmann-Wellenhof R, Johr R, Langford D, Malvehy J, Kolm I, Sgambato A, Puig S, Soyer HP, Kerl H.Nevus type in dermoscopy is related to skin type in white persons.Arch Dermatol. 2007 Mar; $143(3): 351-6$

(8) Zalaudek I, Docimo G, Argenziano G. Using dermoscopic criteria and patient-related factors for the management of pigmented melanocytic nevi. Arch Dermatol. 2009;145:816-826.

(9) Cuéllar F, Puig S, Kolm I et al. Dermoscopic features of melanomas associated with MC1R variants in Spanish CDKN2A mutation carriers. Br J Dermatol. 2009;160:48-53.** Pivotal study demonstrating the influence of high and low susceptibility genes on the dermoscopic appearance of melanoma

(10) Orlow I, Satagopan JM, Berwick M et al. Genetic factors associated with naevus count and dermoscopic patterns: preliminary results from the Study of Nevi in Children (SONIC). Br J Dermatol. 2015;172:1081-1089.

(11) Banan P, Lee KJ, McClenahan P et al. Dermoscopy, reflectance confocal microscopy and histopathology of a melanoma in situ from an individual homozygous for GSTP1*105Val/MC1R*92Met. Australas J Dermatol. 2016;57:64-67.

(12) Fargnoli MC, Sera F, Suppa M et al. Dermoscopic features of cutaneous melanoma are associated with clinical characteristics of patients and tumours and with MC1R genotype. J Eur Acad Dermatol 
Venereol. 2014;28:1768-1775.* large study demonstrating that red hair variants of the MC1R gene influence the morphological appearance of melanocytic skin tumors

(13) Bassoli S, Maurichi A, Rodolfo M et al. CDKN2A and MC1R variants influence dermoscopic and confocal features of benign melanocytic lesions in multiple melanoma patients. Exp Dermatol. 2013;22:411-416.

(14) Quint KD, Van der Rhee JI, Gruis NA et al. Melanocortin 1 Receptor (MC1R) Variants in High Melanoma Risk Patients are Associated with Specific Dermoscopic ABCD Features. Acta Derm Venereol. 2012;92:587-592.

(15) Curchin C, Wurm E, Jagirdar K et al. Dermoscopy, reflectance confocal microscopy and histopathology of an amelanotic melanoma from an individual heterozygous for MC1R and tyrosinase variant alleles. Australas J Dermatol. 2012;53:291-294.

(16) Zalaudek I, Meiklejohn W, Argenziano G et al. "White" nevi and "red" melanomas: association with the RHC phenotype of the MC1R gene. J Invest Dermatol. 2009;129:1305-1307.

(17) De Giorgio V, Savarese I, D'Errico A et al. CDKN2A mutations could influence the dermoscopic pattern of presentation of multiple primary melanoma: a clinical dermoscopic genetic study. J Eur Acad Dermatol Venereol. 2015;29:574-580.

(18) Sturm RA, Fox C, McClenahan P et al. Phenotypic characterization of nevus and tumor patterns in MITF E318K mutation carrier melanoma patients. J Invest Dermatol. 2014; 134:141-149.* First study showing a specific pattern of nevi and melanomas associated with the MITF E318K mutation

(19) Potrony M, Puig-Butille JA, Aguilera P et al. Prevalence of MITF p.E318K in patients with melanoma independent on the presence of CDKN2A causative mutations. JAMA Dermatol. 2015;9:1-8.

(20) Wiesner T, Obenauf AC, Murali R et al. Germline mutations in BAP1 predispose to melanocytic tumors. Nat Genet. 2011;43:1018-1021.** First study describing a novel germline mutation associated with the development of melanocytic tumors with peculiar morphology

(21) Zalaudek I, Catricalà C, Moscarella E et al. What dermoscopy tells us about nevogenesis. J Dermatol. 2011;38:16-24.

(22) Zalaudek I, Hofmann-Wellenhof R, Kittler H et al. A dual concept of nevogenesis: Theoretical considerations based on dermoscopic features of melanocytic nevi. JDDG. 2007;5:985-992.

(23) Michaloglou C, Vredeveld L, Soengas M et al. BRAFE600-associated senescence-like cell cycle arrest of human naevi. Nature. 2005;436:720-724.

(24) Gray-Schopfer V, Cheong S, Chong H et al. Cellular senescence in naevi and immortalisation in melanoma: a role for p16? BrJ Cancer. 2006;95:496-505.

(25) Charbel C, Fontaine RH, Malouf GG et al. NRAS mutation is the sole recurrent somatic mutation in large congenital melanocytic nevi. J Invest Dermatol 2014;134:1067-1074.

(26) Zalaudek I, Guelly C, Pellacani G, Hofmann-Wellenhof R, Trajanoski S, Kittler H, Scope A, Marghoob AA, Longo C, Leinweber B, Ferrara G, Saida T, Grichnik JM, Argenziano G, Becker JC. The dermoscopical and histopathological patterns of nevi correlate with the frequency of BRAF mutations.J Invest Dermatol. 2011 Feb;131(2):542-5.* First study linking BRAF V600E mutations with specific dermoscopic and histopathological features of nevi

(27) Pollock PM, Harper UL, Hansen KS et al. High frequency of BRAF mutations in nevi. Nat Genet. 2003;33:19-20.

(28) Ichii-Nakato N, Takata M, Takayanagi S et al. High frequency of BRAFV600E mutation in acquired nevi and small congenital nevi, but low frequency of mutation in medium-sized congenital nevi. J Invest Dermatol. 2006;126:2111-2118.

(29) Ross AL, Sanchez MI, Grichnik JM. Molecular nevogenesis. Dermatol Res Pract. 2011;6:1-9.

(30) Bauer J, Curtin JA, Pinkel D et al. Congenital melanocytic nevi frequently harbor NRAS mutations but no BRAF mutations. J Invest Dermatol. 2007;127:179-182.

(31) Lin J, Takata M, Murata $\mathrm{H}$ et al. Polyclonality of BRAF mutations in acquired melanocytic nevi. J Natl Cancer Inst 2009;101:1423-1427.

(32) Roh MR, Eliades P, Gupta S et al. Genetics of melanocytic nevi. Pigment Cell Melanoma Res. 2015;28:661-672. 
(33) Damanpour S, Grichnik JM. Conceptual approach to early melanoma detection: models, tools, issues and challenges. Melanoma Manag. 2015;2:327-337.

(34) Pozzobon FC, Puig-Butille JA, Gonzalez-Alvarez T et al. Dermoscopic criteria associated with BRAF and NRAS mutation status in primary cutaneous melanoma. Br J Dermatol. 2014;171:754-759.

(35) Tschandl P, Berghoff AS, Preusser M et al. NRAS and BRAF mutations in melanoma-associated nevi and uninvolved nevi. PLoS One. 2013;8:e69639.

(36) Tschandl P, Berghoff AS, Preusser M et al. Impact of oncogenic BRAF mutations and p16 expression on the growth rate of early melanomas and naevi in vivo. Br J Dermatol. 2016;174:364-370.

(37) Sanchez MI, Rabinovitz HS, Oliviero MC et al. Dark Homogeneous Streak Dermoscopic Pattern Correlating with Specific KIT Mutations in Melanoma. JAMA Dermatol. 2014;150:633-639.

(38) Wu JM, Alvarez H, Garcia P et al. Melanoma hyperpigmentation is strongly associated with KIT alterations. Am J Dermatopathol 2009;31:619-625

(39) Lipsker D, Engel F, Cribier B et al. Trends in melanoma epidemiology suggest three different types of melanoma. Br J Dermatol. 2007;157:338-343.** Introduction of a novel classification of melanoma based on the potential to grow and to metastasize

(40) Lee JH, Choi JW, Kim YS et al. Frequencies of BRAF and NRAS mutations are different in histological types and sites of origin of cutaneous melanoma: a meta-analysis. Br J Dermatol. 2011;164:776784.

(41) Curtin JA, Busam K, Pinkel D et al. Somatic activation of KIT in distinct subtypes of melanoma. J Clin Oncol. 2006;24:4340-4346.

(42) Curtin JA, Fridlyand J, Kageshita T et al. Distinct sets of genetic alterations in melanoma. N Engl J Med. 2005;353:2135-2147.** First study classifying melanoma based on specific genetical alterations

(43) Roma P, Savarese I, Martino A et al. Slow-growing melanoma. Report of five cases. J Dermatol Case Rep. 2007;1:01-03.

(44) Argenziano G, Kittler H, Ferrara G et al. Slow-growing melanoma: a dermoscopy follow-up study. Br J Dermatol. 2010;162:267-273.

(45) Terushkin V, Dusza SW, Scope A et al. Changes observed in slow-growing melanomas during longterm dermoscopic monitoring. Br J Dermatol. 2012;166:1213-1220.

(46) Debarbieux S, Thomas L et al. Superficial spreading melanoma. Ann Dermatol Venereol. 2015;142:66-69.

(47) Menzies SW, Moloney FJ, Byth K et al. Dermoscopic evaluation of nodular melanoma. JAMA Dermatol. 2013;149:699-709.

(48) Zalaudek I, Marghoob AA, Scope A et al. Three roots of melanoma. Arch Dermatol. 2008;144:13751379.

(49) Grichnik JM, Ross AL, Schneider SL et al. How, and from which cell sources, do nevi really develop? Exp Dermatol. 2014;23:310-313.

(50) Giacomel J, Zalaudek I, Mordente I et al. Never perform laser treatment of skin tumors with clinical "EFG" criteria.J Dtsch Dermatol Ges. 2008;6;386-388.

(51) Argenziano G, Longo C, Cameron A et al. Blue-black rule: a simple dermoscopic clue to recognize pigmented nodular melanoma. Br J Dermatol. 2011;165:1251-1255.

(52) Longo C, Farnetani F, Moscarella E et al. Can noninvasive imaging tools potentially predict the risk of ulceration in invasive melanomas showing blue and black colors? Melanoma Res. 2013;23:125131.

(53) Bonnelykke-Behrndtz LM, Schmidt H, Damsgaard TE et al. Consumption of the epidermis: a suggested precursor of ulceration associated with increased proliferation of melanoma cells. Am J Dermatopathol. 2015;37:841-845.

(54) Pizzichetta MA, Kittler H, Stanganelli I et al. Pigmented nodular melanoma: the predictive value of dermoscopic features using multivariate analysis. Br J Dermatol. 2015;173:106-114.

(55) Rosendahl C, Hishon M, Cameron A et al. Nodular melanoma: Five consecutive cases in a general practice with polarized and non-polarized dermatoscopy and dermatopathology. Dermatol Pract Concept. 2014;30:69-75. 
(56) Sequra S, Pellacani G, Puig S et al. In vivo microscopic features of nodular melanomas: dermoscopy, confocal microscopy and histopathological correlates. Arch Dermatol. 2008;144:1311-1320.

(57) Kalkhoran S, Milne O, Zalaudek I et al. Historical, clinical and dermoscopic characteristics of thin nodular melanoma. Arch Dermatol. 2010;146:311-318.

(58) Zalaudek I, Kreusch J, Giacomel J et al. How to diagnose nonpigmented skin tumors: a review of vascular structures seen with dermoscopy: part I. Melanocytic skin tumors. J Am Acad Dermatol. 2010;63:361-374.

(59) Argenziano G, Zalaudek I, Corona R et al. Vascular structures in skin tumors: a dermoscopy study. Arch Dermatol. 2004;140:1485-1489.

(60) Higgins HW $2^{\text {nd }}$, Lee KC, Galan A et al. Melanoma in situ: Part I. Epidemiology, screening and clinical features. J Am Acad Dermatol. 2015;73:181-190.

(61) Lallas A, Tschandl P, Kyrgidis A et al. Dermoscopic clues to differentiate facial lentigo maligna from pigmented actinic keratosis. Br J Dermatol. 2015 [Epub ahead of print].

(62) Lallas A, Argenziano G, Moscarella E et al. Diagnosis and management of facial pigmented macules. Clin Dermatol. 2014;32:94-100.

(63) Zalaudek I, Cota C, Ferrara G et al. Flat pigmented macules on sun-damaged skin of the head/neck: junctional nevus, atypical lentiginous nevus, or melanoma in situ? Clin Dermatol. 2014;32:88-93.

(64) Tiodorovic-Zivkovic D, Zalaudek I, Lallas A et al. The importance of gray color as a dermoscopic clue in facial pigmented lesion evaluation: a case report. Dermatol Pract Concept. 2013;3:37-39.

(65) Ferrara G, Ligrone L, Zalaudek I et al. Lentigo maligna in a young adult. Dermatology. 2008;217:6668.

(66) Zalaudek I, Horn M, Richtig E et al. Local recurrence in melanoma in situ: influence of sex, age, site of involvement and therapeutic modalities. Br J Dermatol. 2003;148:703-708.

(67) Tiodorovic-Zivkovic D, Argenziano G, Lallas A et al. Age, gender and topography influence the clinical and dermoscopic appearance of lentigo maligna. J Am Acad Dermatol. 2015;72:801-808.

(68) Tschandl P, Rosendahl C, Kittler H. Dermatoscopy of flat pigmented facial lesions. J Eur Acad Dermatol Venereol. 2015;29:120-127.

(69) Takata M, Goto Y, Ichii N et al. Constitutive activation oft he mitogen-activated protein kinase signaling pathway in acral melanomas. J Invest Dermatol. 2005;125:318-322.

(70) Saida T, Koga H, Uhara H. Key points in dermoscopic differentiation between early acral melanoma and acral nevus. J Dermatol. 2011;38:25-34.

(71) Saida T, Miyazaki A, Oguchi S et al. Significance of dermoscopic patterns in detecting malignant melanoma on acral volar skin: results of a multicenter study in Japan. Arch Dermatol 2004;140:1233-1238.

(72) Lallas A, Kyrgidis A, Koga $\mathrm{H}$ et al. The BRAAFF checklist: a new dermoscopic algorithm for diagnosing acral melanoma. Br J Dermatol. 2015;173:1041-1049.

(73) Yamaura M, Takata M, Miyazaki A et al. Specific dermoscopy patterns and amplifications of the cyclin D1 gene to define histopathologically unrecognizable early lesions of acral melanoma in situ. Arch Dermatol. 2005;141:1413-1418.

(74) Levit EK, Kagen MH, Scher RK. The ABC rule for clinical detection of subungual melanoma. J Am Acad Dermatol. 2000;42:269-274.

(75) Thomas L, Dalle S. Dermoscopy provides useful information for the management of melanonychia striata. Dermatol Ther. 2007;20:3-10.

(76) Blum A, Simionescu O, Argenziano G et al. Dermoscopy of Pigmented Lesions of the Mucosa and the Mucocutaneous Junction: Results of a Multicenter Study by the International Dermoscopy Society (IDS). Arch Dermatol. 2011;147:1181-1187.

(77) Puig S, Malvehy J. Dermoscopic findings of pigmented lesions of the mucosae. In: Principles of Dermoscopy (Malvehy J, Puig S eds) Barcelona. 2002;289-289.

(78) Stolz W, Braun-Falco O, Bilek P et al. In: Color Atlas of Dermoscopy. Blackwell Publishing. 2002:151-154.

(79) Lin J, Koga H, Takata M et al. Dermoscopy of pigmented lesions on mucocutaneous juntion and mucous membrane. Br J Dermatol. 2009;161:1255-1261. 
(80) Ferrari A, Agozzino M, Ardigò M et al. Dermoscopic and confocal microscopy patterns of vulvar mucosal melanotic macules. J Am Acad Dermatol. 2014;70:81-82.

(81) Cohen PR, Bedikian AY, Kim KB. Appearance of New Vemurafenib-associated Melanocytic Nevi on Normal-appearing Skin: Case Series and a Review of Changing or New Pigmented Lesions in Patients with Metastatic Malignant Melanoma After Initiating Treatment with Vemurafenib. J Clin Aesthet Dermatol. 2013;6:27-37.

(82) Perier Muzet $\mathrm{M}$, Thomas L, Poulalhon $\mathrm{N}$ et al. Melanoma patients under vemurafenib: prospective follow-up of melanocytic lesions by digital dermoscopy. J Invest Dermatol. 2014;134:1351-1358.** First prospective study using digital dermoscopy of melanocytic skin tumors in patients receiving vemurafenib

(83) McClenahan P, Lin LL, Tan JM et al. BRAFV600E mutation status of involuting and stable nevi in dabrafenib therapy with or without trametinib. JAMA Dermatol. 2014;150:1079-1082.

(84) Hatzivassiliou G, Song K, Yen I et al. RAF inhibitors prime wild-type RAF to activate the MAPK pathway and enhance growth. Nature. 2010;464:431-435.

(85) Zalaudek I, Guelly C, Pellacani G et al. The dermoscopical and histopathological patterns of nevi correlate with the frequency of BRAF mutations. J Invest Dermatol. 2011;131:542-545.

(86) Dalle S, Poulalhon N, Debarbieux S et al. Second primary melanomas on treatment with vemurafenib. Br J Dermatol. 2013;168:887-888.

(87) Dalle S, Poulalhon N, Thomas L. Vemurafenib in melanoma with BRAF V600E mutation. N Engl J Med. 2011;365:1448-1449.* First publication reporting on the development of melanoma during vemurafenib treatment

(88) Perier Muzet M, Thomas L, Poulalhon N et al. Melanoma patients under vemurafenib: prospective follow-up of melanocytic lesions by digital dermoscopy. Jnvest Dermatol. 2014;134:1351-1358.

(89) McClenahan P, Lin LL, Tan JM et al. BRAFV600E mutation status of involuting and stable nevi in dabrafenib therapy with or without trametinib. JAMA Dermatol. 2014;150:1079-1082.

(90) Chapman PB, Hauschild A, Robert $C$ et al. Improved survival with vemurafenib in melanoma with BRAF V600E mutation. N Engl J Med. 2011;364:2507-2516.

(91) Zimmer L, Hillen U, Livingstone E et al. Atypical melanocytic proliferations and new primary melanomas in patients with advanced melanoma undergoing selective BRAF inhibition. J Clin Oncol. 2012;30:2375-2383.

(92) Debarbieux S, Dalle S, Depaepe L et al. Second primary melanomas treated with BRAF blockers: study by reflectance confocal microscopy. Br J Dermatol. 2013;168:1230-1235.

(93) Chapman P, Hauschild A, Robert C. Updated overall survival (OS) results for BRIM-3, a phase III randomized, open-label, multicenter trial comparing BRAF inhibitor vemurafenib (vem) with dacarbazine (DTIC) in previously untreated patients with BRAF(V600E)-mutated melanoma. J Clin Oncol. 2012;30:abstract 8502.

(94) Argenziano G, Lallas A, Longo C et al. Dormant melanomas or changing nevi? J Invest Dermatol. 2014;134:1196-1198.

(95) Menzies AM, Long GV, Murali R. Dabrafenib and its potential for the treatment of metastatic melanoma. Drug Des Devel Ther. 2012;6:391-405.

(96) Sibaud V, Lamant L, Maisongrosse $V$ et al. Adverse skin reactions induced by BRAF inhibitors: a systematic review. Ann Dermatol Venereol. 2013;140:510-520.

(97) Niezgoda A, Niezgoda P, Czajkowski R. Novel Approaches to Treatment of Advanced Melanoma: A Review on Targeted Therapy and Immunotherapy. Biomed Res. Int. 2015.

(98) Sadayasu A, Maumi Y, Hayashi Y et al. Dermoscopic features of a case of transient acantholytic dermatosis. Australas J Dermatol. 2016 [Epub ahead of print].

(99) Specchio F, Argenziano G, Tiodorovic-Zivkovic D et al. Dermoscopic clues to diagnose acantholytic dyskeratosis. Dermatol Pract Concept. 2015;5:59-60.

(100) Giacomel J, Zalaudek I, Argenziano G. Dermatoscopy of Grover's disease and solitary acantholytic dyskeratoma shows a brown, star-like pattern. Australas J Dermatol. 2012;53:315316.

(101) Hwang SJ, Carlos G, Wakade D, Byth K, Kong BY, Chou S, Carlino MS, Kefford R, FernandezPenas P. Cutaneous adverse events (AEs) of anti-programmed cell death (PD)-1 therapy in patients 
with metastatic melanoma: A single-institution cohort. J Am Acad Dermatol. 2016 Jan 12. pii: S0190-9622(15)02387-7. doi: 10.1016/j.jaad.2015.10.029. [Epub ahead of print]

(102) Lallas A, Kyrgidis A, Tzellos TG, Apalla Z, Karakyriou E, Karatolias A, Lefaki I, Sotiriou E, loannides D, Argenziano G, Zalaudek I. Accuracy of dermoscopic criteria for the diagnosis of psoriasis, dermatitis, lichen planus and pityriasis rosea.Br J Dermatol. 2012 Jun;166(6):1198-205. 


\section{Figure legends:}

Figure 1: Skintype related nevus patterns: Nevus patterns of persons with a fair skin type (A,B); Nevus pattern of a person with a skin type 3 (C) and 4 (D) according to Fitzpatrick

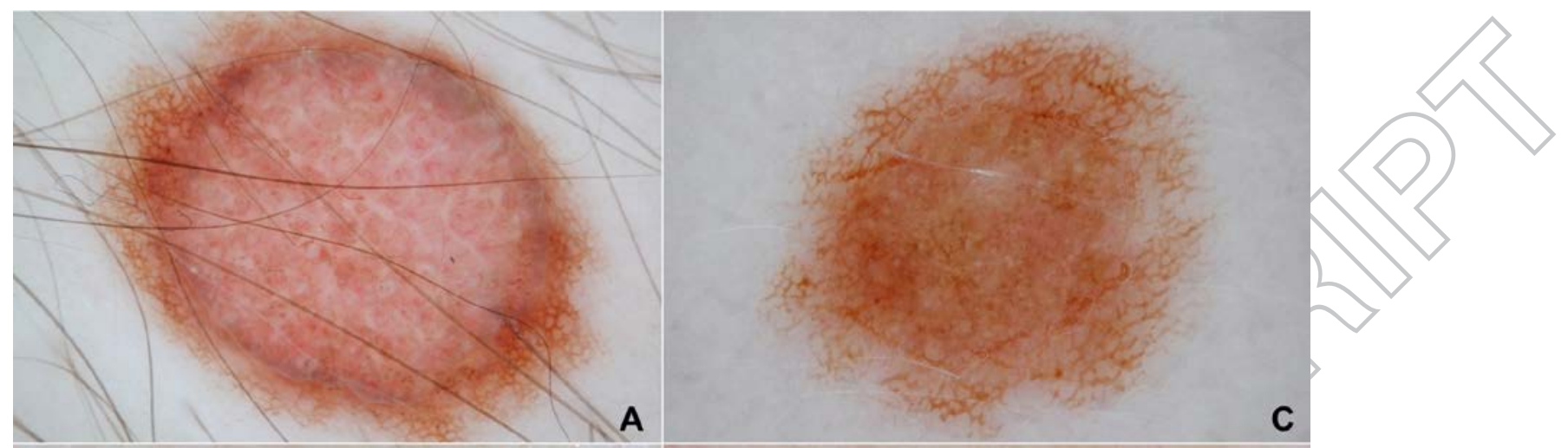

B 
Figure 2: Dermoscopic features of nevi (indicated as N) and melanomas (indicated as MM) excised during a 6 years surveillance program of a male patient with a CDKN2A mutation. Of note, a significant proportion of melanomas have been exclusively detected during digital dermoscopic follow up (indicated as MM-FUP) revealing suspicious, clinically not visible, changes over time.

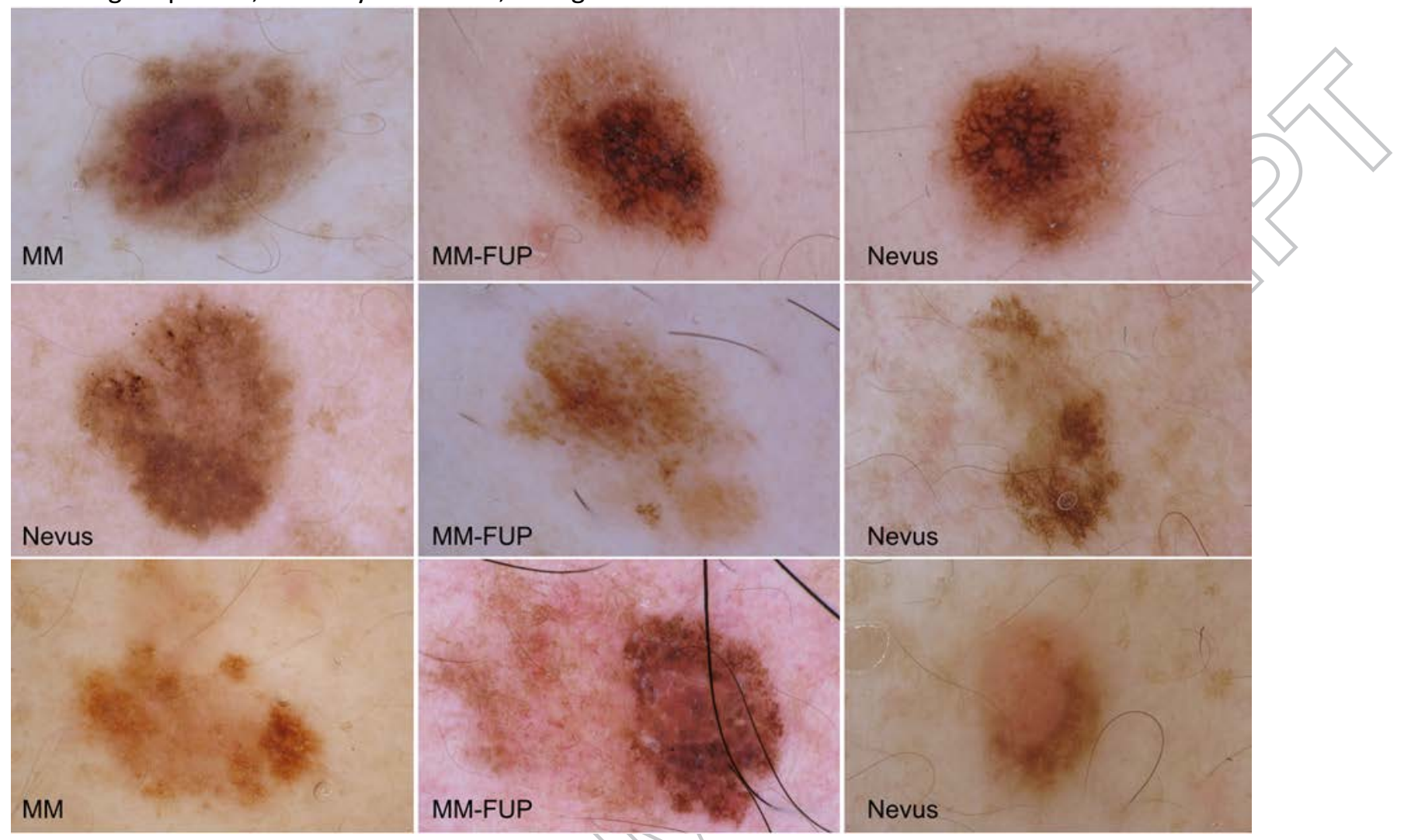


Figure 3: Correlation of reported somatic mutations and clinical-dermoscopic morphology of nevi. (A) Intermediate sized congenital nevus have been associated with mutations in the NRAS gene; (B) Acquired growing compound nevus characterized by small peripheral globules as sign of growth. This nevus revealed a mutation in BRAF V600E; (C) Atypical Spitz nevi have been linked to HRAS mutations. (D) Blue nevi have been linked to mutations in GNAQ.

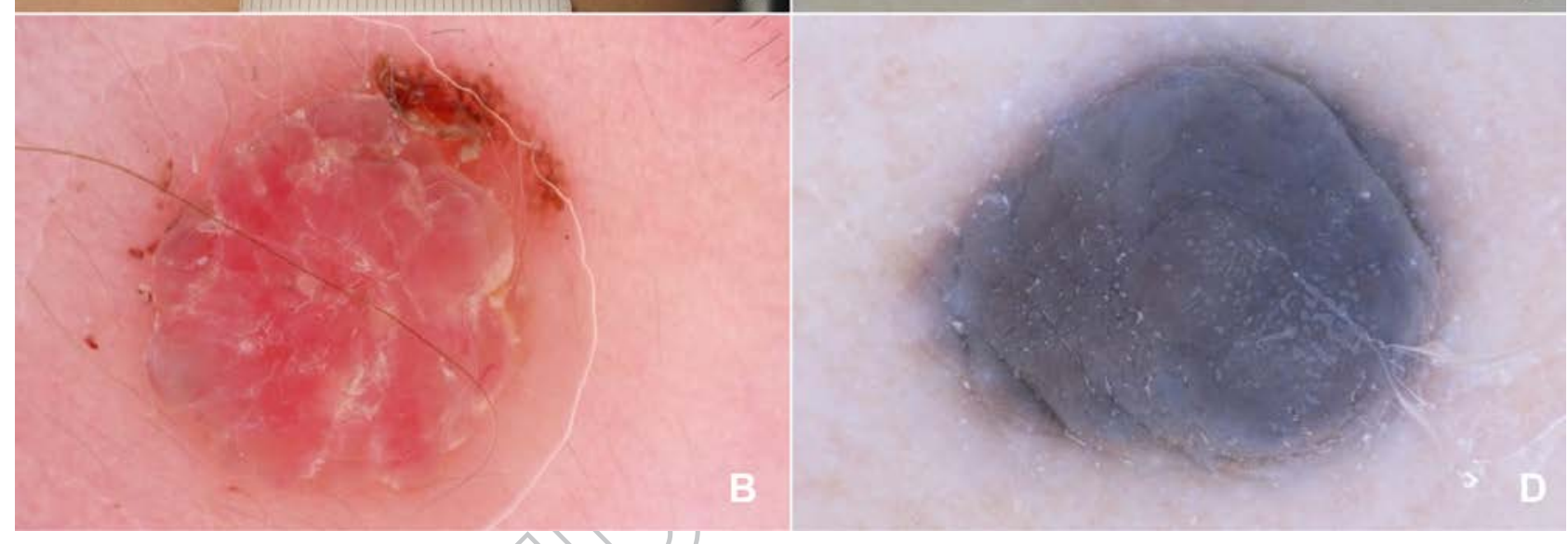


Figure 4: Somatic mutations in melanoma in relation to a specific morphology and topography. (A) BRAF V600E mutated melanoma often reveal signs of regression composed by white and blue-gray structures. (B) Uveal melanoma or malignant blue nevus harbor frequently mutations in GNAQ. (C) Acral and mucosal melanoma often harbor KIT mutations. (D) MITF p.E318K mutations have been associated with an amelanotic phenotype, dermoscopically characterized by atypical vessels.

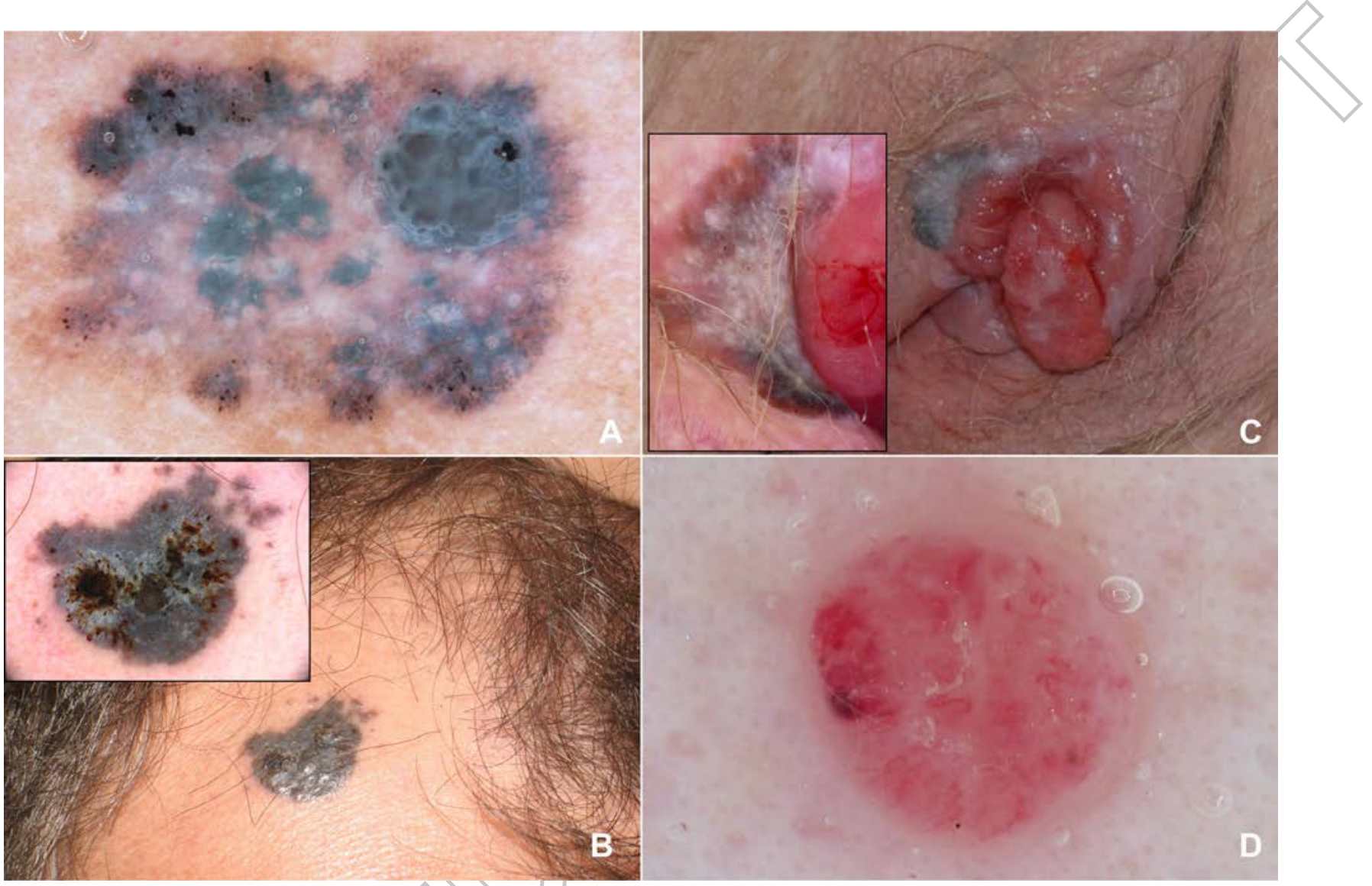


Figure 5: Stereotypical clinical, dermoscopic and histopathological features of slow growing melanoma

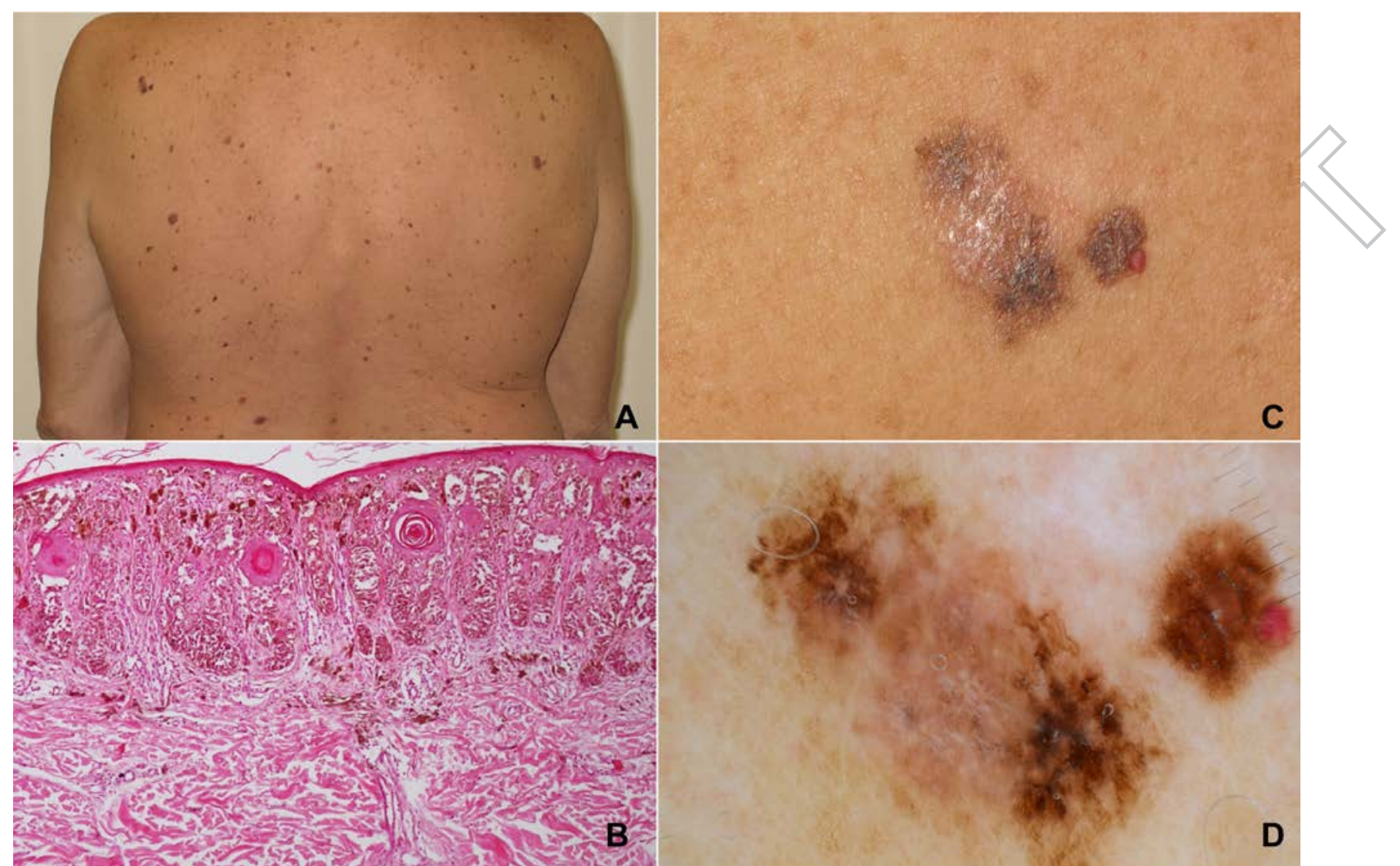


Figure 6: Stereotypical clinical, dermoscopic and histopathological features of pigmented, fast growing melanoma
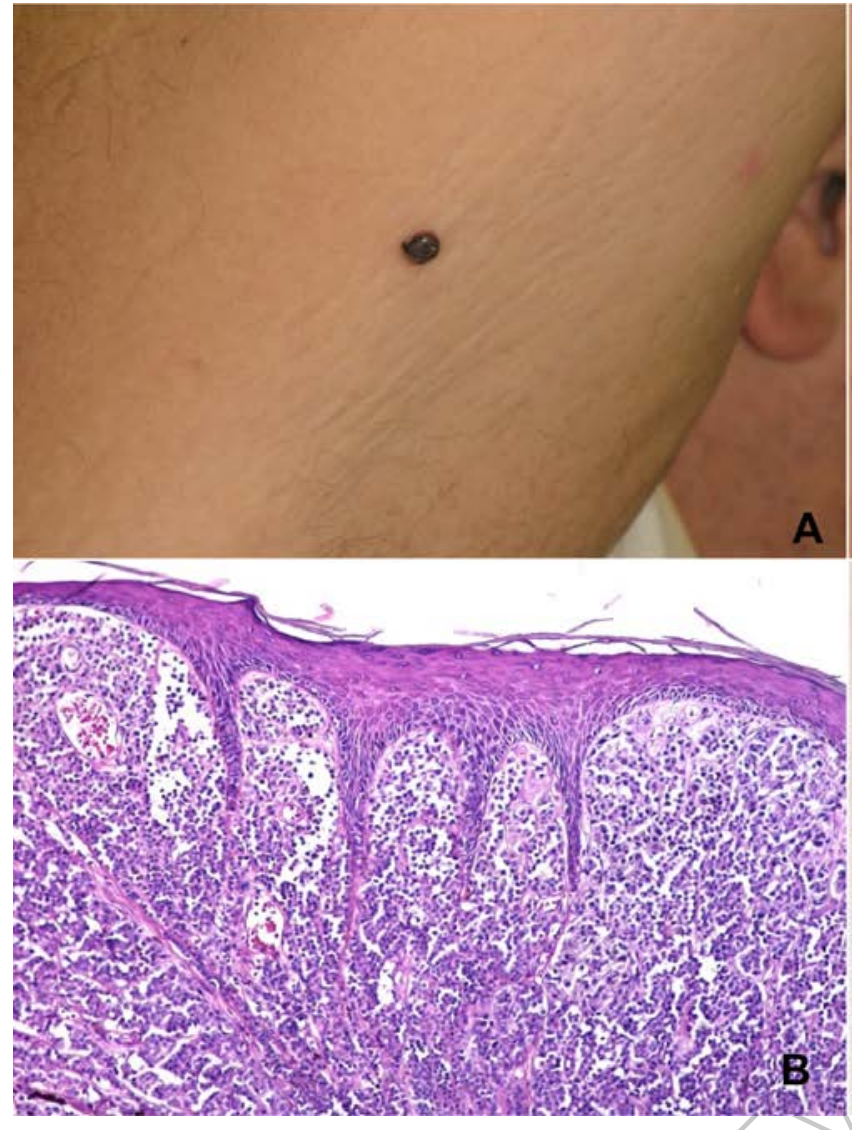

D 
Figure 7: Stereotypical clinical, dermoscopic and histopathological features of lentigo maligna and lentigo maligna melanoma
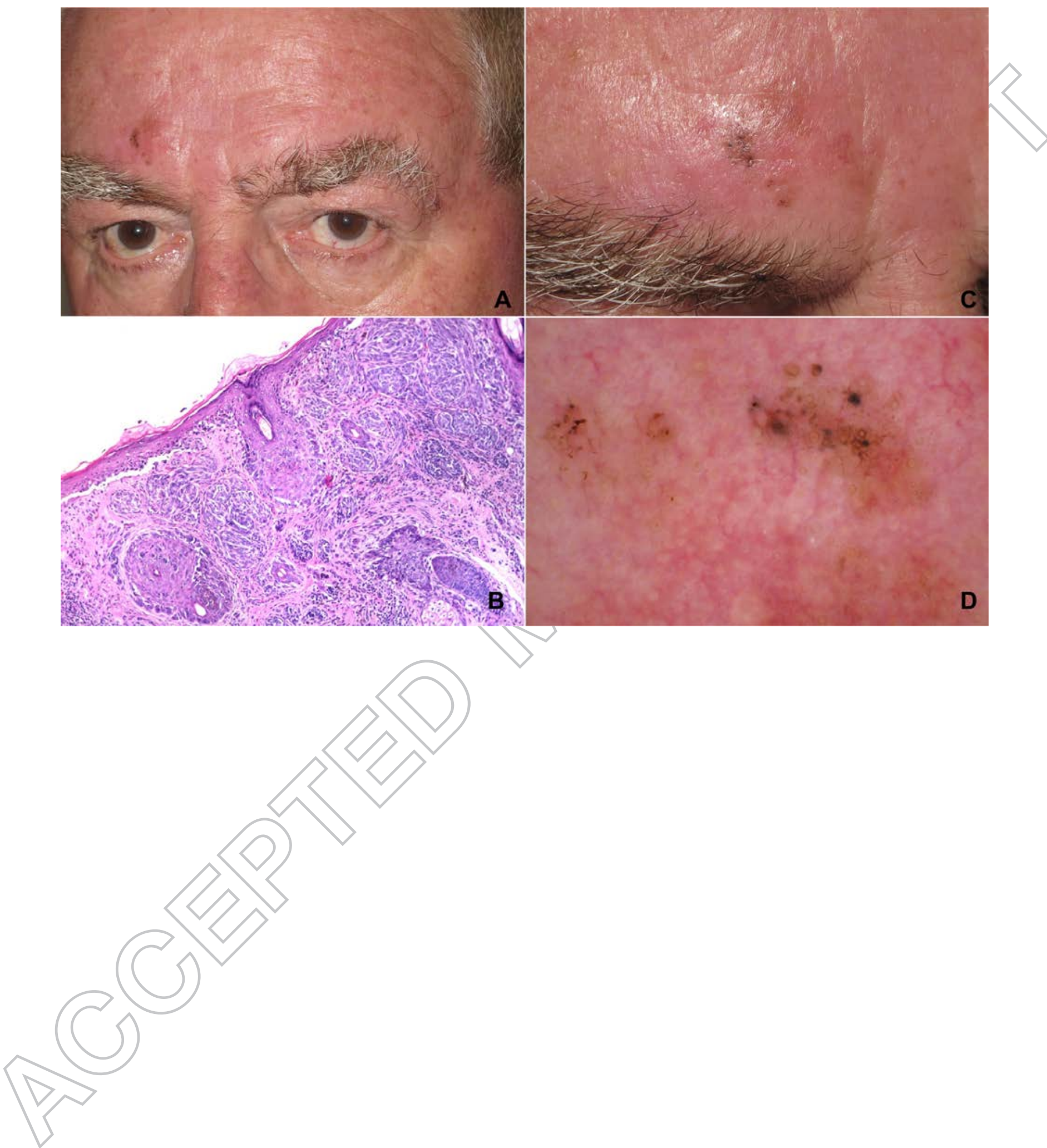
Figure 8: Stereotypical clinical, and dermoscopic patterns of acral $(A, B)$ and subungual $(C, D)$ lentiginous melanoma
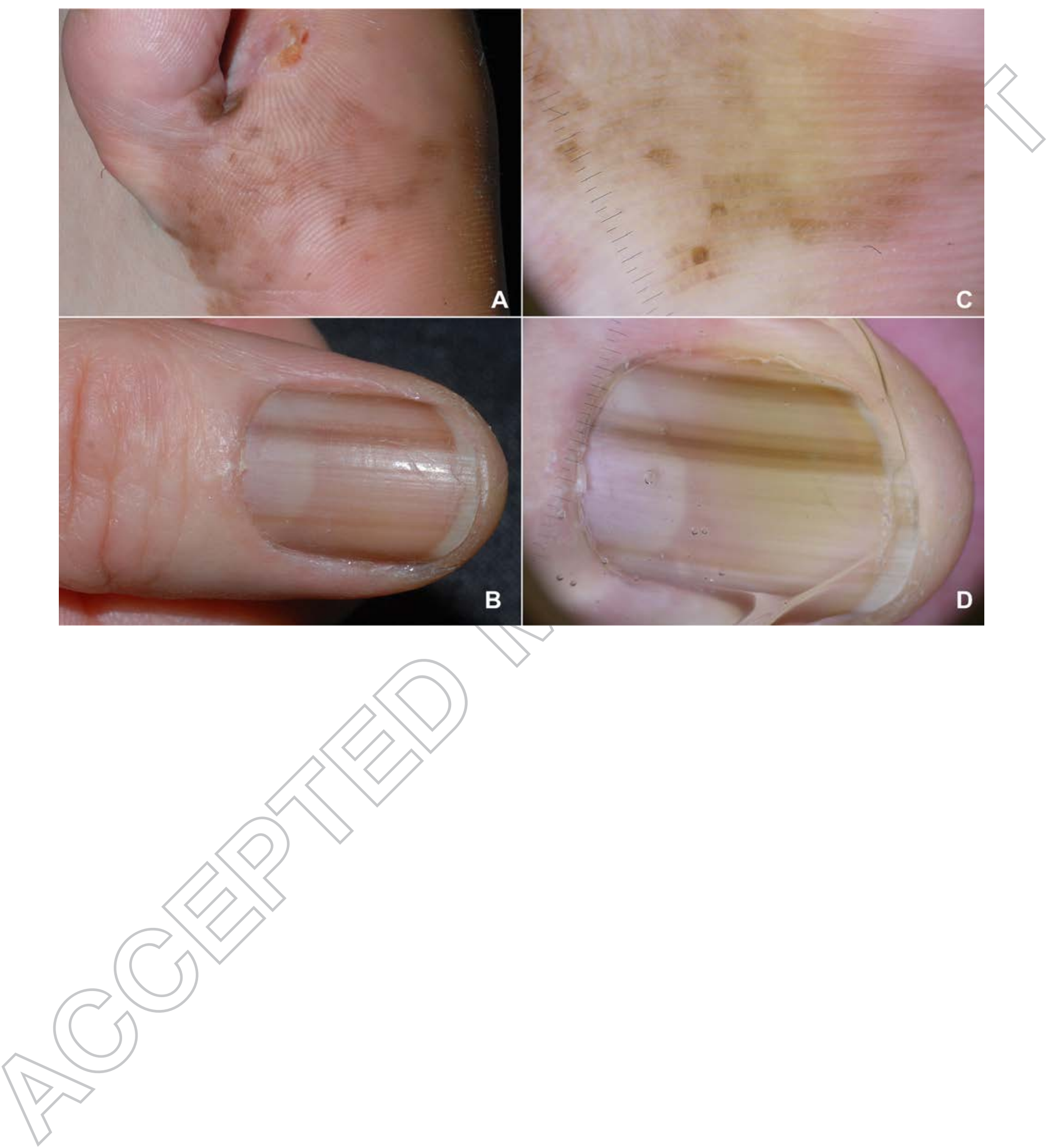
Figure 9: Clinical overview and close up of dermoscopic patterns of cutaneous side effects during treatment with vemurafenib. (A) eruptive nevi commonly show a network pattern and are wt for the BRAF mutations; (B) atypical melanocytic tumor characterized by an inverse network (white small lines forming a network) pattern and growth during treatment; (C) typical feature of a squamous cell carcinoma - keratoacanthoma type; (D) stereotypical appearance of acantholytic dyskeratoma

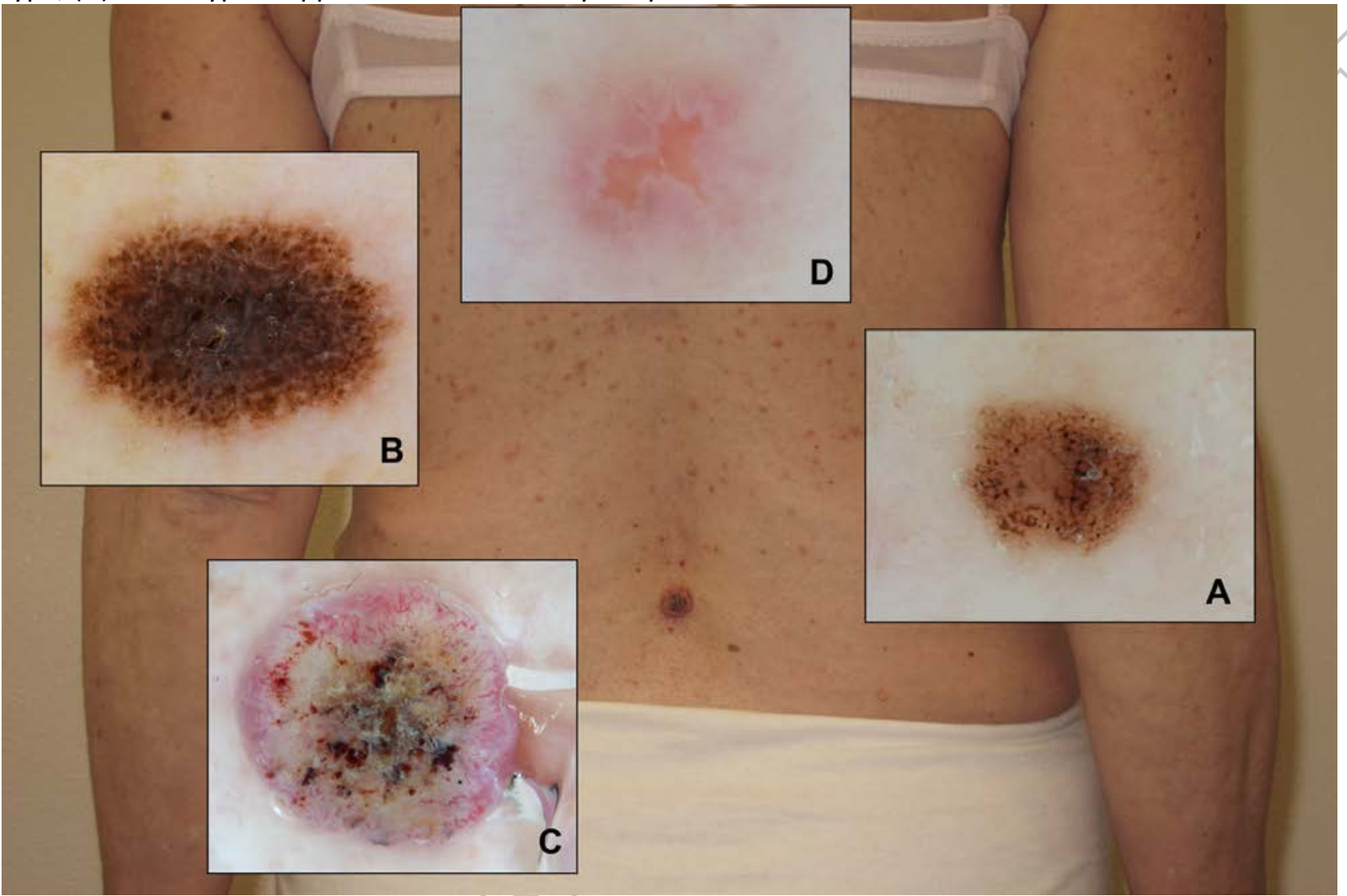


Figure 10: Clinical (A) and dermoscopic features (inserts) of lichenoid reaction observed during treatment with a PD-1 antibody.

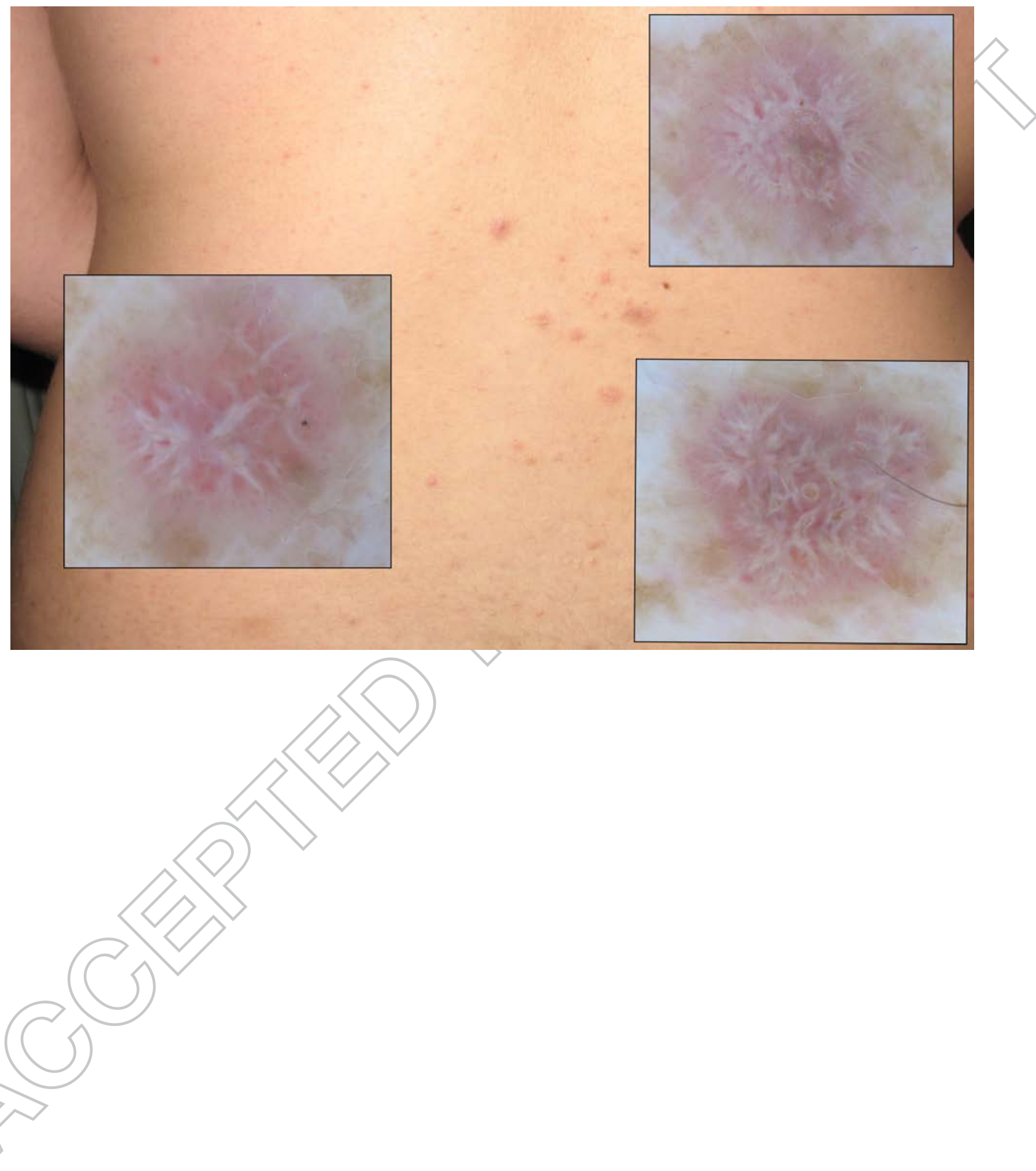

